\title{
Informational Needs among Women with Newly Diagnosed Breast Cancer: Suggested Nursing Guidelines
}

\author{
Soheir Shayboub Sayed, Shalabia El-Sayed Abo Zead, Ghona Abd El-Nasser Ali \& Ahmed El-Sayed \\ Mohamed. \\ Demonstrator of Medical-Surgical Nursing, Faculty of Nursing, Sohag University, Egypt. \\ Prof. of Medical-Surgical Nursing, Faculty of Nursing, Assiut University, Egypt. \\ Assist. Prof, of Medical, Surgical Nursing, Faculty of Nursing, Sohag University, Egypt. \\ lecturer of Oncology, Faculty of Medicine, Sohag University, Egypt.
}

\begin{abstract}
Background: Women with breast cancer require information to help them manage their illness, it assists patients in making treatment decisions and managing immediate effects of treatment. Aim: To identify informational needs among women with newly diagnosed breast cancer and to design a suggested nursing guidelines. Setting: This study was conducted at the outpatient clinic of Sohag Oncology Institute and Sohag University Hospital. Sample: A conveniente sample of (100) adult female patients diagnosed with breast cancer undergoing breast surgery, radiotherapy or chemotherapy the age of patient ranged between (18-65) years old during period of 6 months. Tools: The tools were used for data collection included: An interview questionnaire, Toronto informational needs questionnaire of breast cancer. The suggested nursing guidelines was developed by the researcher. Results: The present study revealed that about (83\%) of the studied patients had unsatisfactory level of knowledge regarding breast cancer. There was a statistically significant difference among chemotherapy \& surgery group between total information needs and educational level.Conclusion: Women with breast cancer lack information especially about their disease, treatments and examinations they are undergoing. Recommendations: Establishment of specialized resource centers in different governerates of Egypt,rural and urban areas for meeting informational needs among women with newly diagnosed breast cancer.
\end{abstract}

Keywords: Breast cancer, Informational Needs, Women\&Toronto Informational Needs Questionnaire.

\section{Introductions}

Breast cancer is the most common cancer in women in most countries and the leading cause of cancerrelated death in women worldwide. The incidence of breast cancer worldwide is predicted to rise to 2.3 million by 2030 , learning what patients want from their healthcare providers is an important step in addressing their concerns and meeting their psychosocial needs ( Harding et al., 2013).

Determining the stage helps determine the best way to contain and eliminate the breast cancer. Stage $0 \&$ 1 represent the earliest detection of breast cancer development. At Stage 0 and 1, the cancer cells are confined to a very limited area. Stage 2 And Stage $2 \mathrm{~A}$ is still in the earlier stages, but there is evidence that the cancer has begun to grow or spread. It is still contained to the breast area and is generally very effectively treated. Stage 3 A, B, And C is considered advanced cancer with evidence of cancer invading surrounding tissues near the breast. Stage 4 indicates that cancer has spread beyond the breast to other areas of the body (Smeltzer et al., 2014)

Breast cancer and its treatment cause emotional trauma and health complaints. These lead to supportive care needs in some patients, while others are more able to cope with th ese consequences themselves. To be able to address these needs, it is important to identify patients' needs at the time they arise (Büchi et al., 2013).

Research studies on information needs and information-sharing in patients with cancer have been increasing steadily in the past 3 decades. These studies relating to patient information-sharing were aimed at improving patient education and ultimately increasing patient participation in health-care decision-making (Tariman et al., 2014).

Today, understanding is growing about the importance of involving cancer patients in decisionmaking about their care with that understanding comes the need for additional information on diagnosis, prognosis, and treatment options to support patients and their families in making informed decisions (SheaBudgell et al., 2014).

Information seeking has been demonstrated to play a critical role in individuals' efforts to cope with the disruption of the quality of life associated with cancer diagnosis and treatment. Obtaining information, particularly regarding prognosis and treatment, remains a major area of need for individuals with cancer (Nagler et al., 2010). In order for information to be useful, there is a need to understand the nature of information that patients and their partners require ( Kassianos et al., 2016). 


\section{Significance of the study}

An estimated number of patients with breast cancer in Egypt 2015 are 19411 patients and 19105 in females according to Results of the National PopulationBased Cancer Registry Program. There were 146 patients diagnosed with breast cancer in Sohag University hospital (Sohag Hospital Record,2014). Knowledge of what women need at different points in the course of treatment of breast cancer methods can only come from asking the women themselves.

\section{Aims of the study}

This study aimed to identify informational needs among newly diagnosed breast cancer patients,design and implement suggested nursing guidelines.

\section{Subjects \& Methods \\ Research Design}

A descriptive research design was utilized in this study.

\section{Setting of the Study}

This study was conducted at the outpatient clinic of Sohag Oncology Institute and University Hospital

\section{Study Sample}

A conveniente sample of (100) adult female patients newly diagnosed with breast cancer undergoing breast surgery, radiotherapy or chemotherapy who are willing to participate in the study, mean age \pm mean SD was $51.23 \pm 13.71$ years during period of 6 months were included in this study.

\section{Sample size using power analysis}

Sample size was estimated with statistical program (Mini tab 17) and determined according to this equation:

$\frac{\mathrm{Ss}=\mathrm{Z} 2 \mathrm{P}(1-\mathrm{p})}{\mathrm{C} 2}$

Where $\mathrm{Z}=1.96$

$$
\mathrm{c}=0.08 \quad \mathrm{p}=0.5
$$

New ss $=$ ss

$(1+\mathrm{ss}-1)$

$$
\text { (Pop) }
$$

(Pop) is the population $=250$,New ss=94

Minimal required sample $=94$

\section{Study Tools:}

Data of this study was collected by using the following tools:

\section{Tool (I) : A structured interview questionnaire}

It was designed by the researcher based on literature review, including two parts:

Part I : Included demograghic data items as: (age,educational level, marital status, residence and occupation) .

Part II : Included medical related data items as:(duration, stages, treatment of disease, type of tumer, family history and nature of complaints) . part III : Included knowledge about breast cancer, there were some opening questions as: (definition of breast cancer, definition of radiotherapy and chemotherapy and there were other closed questions as: (source of information, causes, treatment, care after operation, different surgeries, wound care after operation and complications for different breast cancer treatment.

Tool (II) : Toronto informational needs questionnaire of breast cancer

It was developed by Yi et al., (2007) to elicit women's perception of their informational needs related to their experience of breast cancer. Toronto questionnaire was translated into Arabic language for easily understanding by women. Toronto questionnaire comprised of a 52-item, measuring the following five subscales of informational needs: disease, treatment, investigative tests, physical and psychosocial needs.

\section{Scoring System}

Each item was scored as a 5-point Likert Scale as: 1 $=$ not important, $2=$ slightly important, $3=$ moderately important, $4=$ highly important, and $5=$ extremely important.statistical presentations of data was derived from collapsing the original scale to 3 scale: $1=$ not important+slightly important, $2=$ moderately important and, 3 = highly+extremely important. Less than $50 \%$ is considered low important, $50 \%$ to $70 \%$ is considered moderately important, more than $70 \%$ is considered highly important. Total score with minimum of 52 and maximum of 208, the higher scores represent higher information needs

Scoring system of the present study about knowledge about breast cancer

It contains 9 questions the scoring process of it was:each correct answer took 1 score and zero for incorrect answer.

The total score was divided in to two levels:-

- Score less than50\% was considered unsatisfactory.

- Score above 50\% was considered satisfactory.

\section{Suggested Guidelines:}

It was designed by the researcher from literature reviews based on patient's assessment informational needs and covers definition,stages of breast cancer, treatments, tests, breast cancer modalities and importance of breast surgery, radiotherapy and chemotherapy management and follow up. American cancer society, (2016)

\section{Methods}

An official approval and administration permission were obtained from the Dean of Faculty of Nursing at Sohag University and the head of the outpatient clinic of Sohag Oncology Institute and University Hospital to collect the necessary data,, an oral consent was obtained from patients to participate in the study and the nature and purpose of the study 
were explained to them, confidentialty and anonymity were assured.

\section{Field work}

The interview questionnaire sheets were filled by researcher while patients at the outpatient clinic of Sohag Oncology Institute and University Hospital in the morning. Purpose of the study was explained prior to elaborate the questionnaire tools. Each patient involved in the study was interviewed to answer the Toronto informational needs questionnaire tool in the morning. Sampling was started and completed within 6 months from December 2015 till June 2016.Each patient had a copy of suggested nursing guidelines and had been explained for her, and covers definition, stages of breast cancer, treatments, tests, breast cancer modalities and importance of breast surgery, radiotherapy and chemotherapy management and follow up.

\section{Content validity and reliability}

It was established by panel of five experts in the field of Medical Surgical Nursing Specialty who reviewed the instrument and nursing guidelines for clarity, relevance,comprehensiveness and applicability.The content validity of this tool was checked by expert professor in medical surgical nursing and correction was carried out accordingly. Then the final form of tool2 Toronto scale was designed and tested for reliability by using internal consistency for the tools measured using cronbach test, the tool proved to be reliable (cronbach's Alpha $=0.96$ ).

\section{Apilot study}

Pilot study was conducted on $10 \%$ of the study sample (10) women in aselected setting to evaluate the applicability \&clarity of the tools. According to this pilot study, the required modifications were made. Those patients who were involved in the pilot study were not included in the study.

\section{Statistical design}

The collected data were tabulated and statistically analyzed to assess informational needs among women with newly diagnosed breast cancer under study as regards the various variables by computer program SPSS" ver 16" Chicago USA Data expressed as numbers and percentage, using likelihood ratio to determine significant for the group.

$\mathrm{P}>0.05$ non- significant.

$\mathrm{P} \leq 0.05$ significant.

$\mathrm{P} \leq 0.001$ highly significant.

\section{Ethical considerations}

The study was approved by an institutional ethics committee.

- An oral consent was obtained from patient to participate in the study after the nature and purpose of the study were explained.
- The researcher initialy introduced herself to all optional subjects and she was assured that the collected data would be absolutely confidential.

- Patient were informed that participation is voluntary and that they could withdraw at any time of the study.

- Confidentialty of the patients data was ascertained. Confidentialty and anonymity were assured. Then, through this patient interview, baseline data was obtained from the studied patients to fill in Tool I and Tool II. 


\section{Results}

Table (1): Distribution of demographic characteristics of the studied patients $(n=100)$.

\begin{tabular}{|c|c|c|}
\hline Items & No & $\%$ \\
\hline \multicolumn{3}{|l|}{ Age:(years) } \\
\hline $18-<35$ years & 18 & 18 \\
\hline $35-<50$ years & 44 & 44 \\
\hline $50-<65$ years & 38 & 38 \\
\hline Mean \pm SD & \multicolumn{2}{|c|}{$\frac{1}{51.23 \pm 13.71}$} \\
\hline \multicolumn{3}{|l|}{ Educational level } \\
\hline Illiterate & 60 & 60 \\
\hline Basic education & 20 & 20 \\
\hline Secondary & 6 & 6 \\
\hline University or higher & 14 & 14 \\
\hline \multicolumn{3}{|l|}{ Marital status } \\
\hline Single & 11 & 11 \\
\hline Married & 60 & 60 \\
\hline Divorced & 3 & 3 \\
\hline Widow & 26 & 26 \\
\hline \multicolumn{3}{|l|}{ Residence } \\
\hline Rural & 34 & 34 \\
\hline Urban & 66 & 66 \\
\hline \multicolumn{3}{|l|}{ Occupation } \\
\hline Working & 13 & 13 \\
\hline Not working & 87 & 87 \\
\hline
\end{tabular}

Table (2): Distribution of medical data of the studied patients $(n=100)$.

\begin{tabular}{|c|c|c|}
\hline Items & No & $\%$ \\
\hline \multicolumn{3}{|l|}{ Duration of disease } \\
\hline$<1$ year & 100 & 100 \\
\hline$>1$ year & 0 & 0 \\
\hline \multicolumn{3}{|l|}{ Stages of diseas } \\
\hline Stage 0 & 0 & 0 \\
\hline Stage 1 & 22 & 22 \\
\hline Stage 2 & 35 & 35 \\
\hline Stage 3 & 32 & 32 \\
\hline Stage 4 & 11 & 11 \\
\hline \multicolumn{3}{|l|}{ Types of treatment modalities } \\
\hline Chemotherapy & 40 & 40 \\
\hline Chemotherapy \& surgery & 5 & 5 \\
\hline Radiotherapy & 14 & 14 \\
\hline Surgery & 41 & 41 \\
\hline \multicolumn{3}{|l|}{ Types of tumor } \\
\hline Spread & 20 & 20 \\
\hline Non-spread & 80 & 80 \\
\hline \multicolumn{3}{|l|}{ Family history of cancer } \\
\hline Yes & 59 & 59 \\
\hline No & 35 & 35 \\
\hline Don't know & 6 & 6 \\
\hline \multicolumn{3}{|l|}{ Nature of complaints at the first time } \\
\hline Pain & 2 & 2 \\
\hline Lump in a breast & 54 & 54 \\
\hline Pain with lump in a breast & 42 & 42 \\
\hline Lump in abreast with nipple discharge & 2 & 2 \\
\hline
\end{tabular}


Table (3): Assessing knowledge of the studied patients about breast cancer $(n=100)$.

\begin{tabular}{|c|c|c|}
\hline Items & No & $\%$ \\
\hline \multicolumn{3}{|l|}{ Definition of breast cancer } \\
\hline Correct & 40 & 40 \\
\hline Incorrect & 60 & 60 \\
\hline \multicolumn{3}{|l|}{ Source of information } \\
\hline Neighbors & 18 & 45 \\
\hline Friends & 5 & 12.5 \\
\hline TV & 23 & 57.5 \\
\hline Doctor & 13 & 32.5 \\
\hline \multicolumn{3}{|l|}{ Causes of breast cancer } \\
\hline Correct & 1 & 1 \\
\hline Incorrect & 99 & 99 \\
\hline \multicolumn{3}{|l|}{ Treatment of breast cancer } \\
\hline Correct & 65 & 65 \\
\hline Incorrect & 35 & 35 \\
\hline \multicolumn{3}{|l|}{ Type of treatment } \\
\hline Surgery & 57 & 87.7 \\
\hline Radiotherapy & 42 & 64.6 \\
\hline Drugs & 19 & 29.2 \\
\hline \multicolumn{3}{|l|}{ Breast cancer care after operation } \\
\hline Correct & 2 & 2 \\
\hline Incorrect & 98 & 98 \\
\hline \multicolumn{3}{|l|}{ Breast cancer different surgeries } \\
\hline Correct & 2 & 2 \\
\hline Incorrect & 98 & 98 \\
\hline \multicolumn{3}{|l|}{ Wound care after operation } \\
\hline Correct & 1 & 1 \\
\hline Incorrect & 99 & 99 \\
\hline \multicolumn{3}{|l|}{ Definition of radiotherapy } \\
\hline Correct & 10 & 10 \\
\hline Incorrect & 90 & 90 \\
\hline \multicolumn{3}{|l|}{ Definition of chemotherapy } \\
\hline Correct & 33 & 33 \\
\hline Incorrect & 67 & 67 \\
\hline \multicolumn{3}{|c|}{ Complications for different breast cancer treatment } \\
\hline Correct & 11 & 11 \\
\hline Incorrect & 89 & 89.0 \\
\hline
\end{tabular}

Table (5): Total informational need according to Toronto scale for the studied patients $(n=100)$.

\begin{tabular}{|l|c|c|}
\hline \multicolumn{1}{|c|}{ Items } & No. & \multicolumn{2}{|c|}{$\%$} \\
\hline Disease & \multicolumn{2}{|c|}{} \\
\hline Low important & 12 & 2 \\
\hline Moderate important & 86 & 86 \\
\hline High important & \multicolumn{2}{|c|}{} \\
\hline Examination & 5 & 5 \\
\hline Low important & 30 & 30 \\
\hline Moderate important & 65 & 65 \\
\hline High important & \multicolumn{2}{|}{} \\
\hline Treatment & 1 & 1 \\
\hline Low important & & \\
\hline
\end{tabular}




\begin{tabular}{|l|c|c|}
\hline \multicolumn{1}{|c|}{ Items } & No. & \% \\
\hline Moderate important & 7 & 7 \\
\hline High important & 92 & 02 \\
\hline Physical: & \multicolumn{2}{|c|}{} \\
\hline Low important & 0 & 36 \\
\hline Moderate important & 36 & 64 \\
\hline High important & 64 & 0 \\
\hline Psychosocial: & 0 & 40 \\
\hline Low important & 40 & 60 \\
\hline Moderate important & 60 & \\
\hline High important & 0 & \\
\hline
\end{tabular}

Table (8): Relation between demographic data of the studied patients and the total informational needs $(n=100)$.

\begin{tabular}{|l|c|c|c|c|c|c|c|c|c|c|}
\hline \multirow{2}{*}{ Items } & \multicolumn{2}{|c|}{ Age (years) } & \multicolumn{2}{c|}{ Educational level } & \multicolumn{2}{c|}{ Marital status } & \multicolumn{2}{c|}{ Residence } & \multicolumn{2}{c|}{ Occupation } \\
\cline { 2 - 12 } & F-val ue & P-value & F-value & P-value & F-value & P-value & F-value & P-value & F-value & P-value \\
\hline Chemotherapy & 1.889 & 0.166 & 0.259 & 0.773 & 1.780 & 0.183 & 0.428 & 0.517 & 0.387 & 0.538 \\
\hline $\begin{array}{l}\text { Chemotherapy \& } \\
\text { surgery }\end{array}$ & 0.332 & 0.605 & $\mathbf{1 0 . 4 9 9}$ & $\mathbf{0 . 0 4 8}$ & 1.676 & 0.286 & 0.466 & 0.544 & $\mathbf{1 0 . 4 9 9}$ & $\mathbf{0 . 0 4 8 *}$ \\
\hline Radiotherapy & 2.544 & 0.124 & 1.287 & 0.315 & 2.008 & 0.182 & 0.024 & 0.878 & 2.623 & 0.131 \\
\hline Surgery & 0.638 & 0.534 & 0.373 & 0.691 & 0.941 & 0.399 & 1.282 & 0.264 & 1.330 & 0.256 \\
\hline
\end{tabular}

Table (1): showed that the mean age of the studied patients was 51.23 years. Also, $60 \%$ of them were illiterate and married. It was clear that about more than half $(66 \%)$ of them were from urban areas, and only $13 \%$ of them were employees.

Table (2): showed that (35\%) of the studied patients were in stage 2 of disease, regarding types of treatment modalities $(41 \%)$ of the studied patients underwent surgery, and the majority had non spreading tumor, it also shows that more than half of the studied patients (59\%) were having a family history of cancer and had lump in a breast at the first time (54\%).

Table(3): demonstrated that about 60\%, 99\%, 98\%, $98 \%, 99 \%$ \& $90 \%$ respectively of the studied patients had no information regarding definition, causes of breast cancer,care after operation, different surgeries, wound care after operation and definition of radiotherapy respectively, Also, it was found that more than half of them $57.5 \%$ their source of information was T.V.

Table (5): showed that $(86 \% \& 92 \%)$ of the studied patients had high important information need regarding to disease and treatment. $65 \%, 64 \% \& 60 \%$ had highly important need of information regarding to examination, physical and psychosocial parameters of Toronto scale.

Table (8): showed that there was a statistically significant difference between chemotherapy \& surgery group regarding total information needs and educational level $\mathrm{P}<0.05$ and there was a statistically significant difference between total information needs and occupation $\mathrm{P}<0.05$.

\section{Discussion}

Part I: demographic characteristics

The present study clarified that the mean age of the studied patients was around fifty years. The majority of patients were married and not working. These results approximately congruent with Bei et al., (2015) who studied the factors in the prioritization of information needs among breast cancer patient and mentioned in their results that the mean age of participants was around fifty years. Also, Polly et al., (2011) in their study mentioned that breast cancer is the most common cancer among women with age around 50 years. Tracee, (2009) supported that study finding when mentioned that breast cancer risk increases with age. Dolinsky, \& Hill-Kayser, (2008) concluded that the most important risk factor for development of breast cancer is increasing age. Zaid et al., (2016) research has shown that breast cancer can strike at any age and becomes more prevalent with increasing age.

The majority of the sample were married, not employed congruent with Mohamed \& El-Sebaee., (2013) who stated in their study that the majority of the sample were housewives and married.Also, The present study mentioned that most of the studied patients were illiterate.This finding consistent with Abd El-Razik, (2010), whose study revealed that the highest percentage of the breast cancer patients were illiterate regardless of the type of surgery. So more attention has to be paid in designing educational materials for breast cancer patients who are illiterate or less educated. 
In this study the highest percentage of the studied patients were living in urban areas, it might be due to the more exposure to regional environmental air pollutants. This study finding is congruent with Mohamed \& El-Sebaee, (2013) \& Pakseresht et al., (2009) who stated that, large number of breast cancer patients were living in urban areas. These findings were supported by Dey et al., (2011) who concluded that the incidence rate of breast cancer was three to four times higher in urban areas than in rural areas across all age-groups.

\section{Part II -Medical data}

The present study found that the highest percentage of the studied patients were in second stage and this is because of seeking medical advice at late stage and a lot of time consumed to confirm diagnosis, this result is in line with Yi et al., (2007) who reported in their study findings that more than half of the studied group were diagnosed at the second stage. Also, ElShinawi et al., (2013) added that in general, most of egyptian patients diagnosed at an advanced stage .

Findings of this study revealed that the majority of the studied patients have family history of breast cancer. This result goes in line with American Cancer Society, (2012) that mentioned; breast cancer increases with an increasing risk factors including family history. Also, El-Shinawi et al., (2013) stated that almost half of women had a family member with breast cancer.

Regarding reason of attention to breast cancer,patients observed the presence of breast mass.This result is in agreement with astudy by Sandhu et al., (2010) who emphasized that lump in the breast was a dominant symptom. El-Shinawi et al.,(2013) stated that the majority of patients recognized apainless breast mass as abreast cancer symptom.

\section{Part III - knowledge of studied patient}

Regarding sources of knowledge about breast cancer, the present study revealed that more half of the studied patients gained their knowledge from social media. This result goes in agreement with Montazeri et al., (2008) who mentioned that most of the respondents' source of information about breast cancer was from electronic media (television and radio). Syeed., (2011) reported that most of patients had gained the information from the electronic media. The present finding differed with Huang \& Penson., (2008) who found that health-care professionals are still the main source of information used by cancer patients. As well as Zaid et al., (2016) who mentioned that the respondents mainly utilized information from their personal doctors, oncologists, family and friends and nutritionists, and found information from these sources very helpful.
Part IV- informational needs related to disease, examination, treatment, physical and psychosocial aspects

As regard to importance needs of information among the patients under study, the study findings showed that information needs about treatment was first, disease was second and examinations was third, this result goes in line with Graydon et al., (1997) who concluded that all breast cancer women wanted information about their disease, treatments and investigative tests. Also, Nagler et al., (2010) stated that patients most frequently reported seeking about treatment information, but they desired information about other topics too including their chances of survival or cure. Bei et al., (2015) mentioned that extent of the disease was the second most common item of information needs. Kimiafar, et al., (2016) stated that eighty-five percent of patients desired more information about their disease. ValeroAguilera et al., (2014) results showed that women with breast cancer are more interested in information about the risks and benefits of the treatment in the long term. In addition Zaid et al., (2016) stated that the women gave more emphasis to three main types of information: treatment, management and self-care. Polly et al., (2011) stated that the priority of participants information needs was centered on aspects of disease and treatment rather than on sexual attractiveness. According to Syeed, (2011) among all participants more than half respondents said that breast cancer screening is very important.

The study results represented a significant relation between education and total information needs, this goes in line with Mohamed \& El-Sebaee, (2013) who found that educational level had a statisticaly significant relation with total information needs. This may be due to that educated patients have more awareness to their health conditions than noneducated and want to know more about their health status. Also, Bei et al., (2015) stated that patients with a higher educational level are more eager to know more about their treatment options and the associated advantages and disadvantages.

\section{Conclusion}

Newly diagnosed breast cancer women had high important informational needs regarding to disease, treatment, examination, physical and psychosocial domains. Patient knowledge regarding breast cancer were inadequate. It was found that educational level had a statistically significant relation with total informational needs. Also, it was found that occupation had a statistically significant relation with total informational needs. So the specialized designed nursing guidelines meeting the information needs of breast cancer patients are crucial for implementing 
the quality of self care among such groups of patients.

\section{Recommendations}

Based on the findings of the present study the following recommendations are suggested 1-Establishment of specialized resource centers in different governerates of Egypt,rural and urban areas for meeting informational needs among women with newly diagnosed breast cancer.

2-Specific information on recurrence should be offered to all women with breast cancer.

3-Further study is recommended to evaluate the effect of implementing nursing guidelines on the quality of self care among women with breast cancer.

\section{References}

1. Abd El- Razik, S., (2010): Effect of Educational Program on Quality of Life for Patients with Cancer undergoing Chemotherapy, Thesis for Doctoral Degree in Nursing Science, MedicalSurgical Nursing, Faculty of Nursing, Benha University, p. 68.

2. American Cancer Society, (2012): Cancer Facts and Figures. Atlanta, $\mathrm{Ga}$ :AmericanCancerSociety, available from:http://WWW.cancer.org/acs.group/@epide miologysurveilance/documents/documentacspc031941.pdf.

3. American cancer society. (2016): Breast Cancer.available at https://old.cancer.org. access at (April,2016)

4. Bei, A., Lai, M.,Choi, K., \& So, W., ( 2015): Factors in the prioritization of information needs among Hong Kong Chinese breast cancer patients; Asia Pac J Oncol Nurs, Vol.2 (3): pp176-185.

5. Büchi ' S., Halfens, R., Müller, M., Dassen, T., \& Borne, B., (2013): Factors associated with supportive care needs of patients under treatment for breast cancer ,Eur J Oncol Nurs. Vol. 17 (1): pp 22-29.

6. Dey, S., Zhang, Z., Hablas, A., Seifeldein, I., Ramadan, M., \& El-Hamzawy, H., (2011): Geographic patterns of cancer in the populationbased registry of Egypt: Possible links to environmental exposures, Elsevier Inc. ,Vol .35 (3): pp 254-264.

7. Dolinsky, C., \& Hill-Kayser, C., (2008): Breast Cancer: The Basics, Abramson Cancer Center of the University of Pennsylvania available at: http://www.OncoLink.breast.

8. El-Shinawi. M., Youssef, A., Alsara, M., Aly, M., Mostafa, M., Yehia, A., Hurlbert, M., Abd El-Tawab, R., \& Mohamed, M., (2013): Assessing the level of breast cancer awareness among recently diagnosed patients in Ain Shams University Hospital, The Breast, Vol .22: pp 1210-1214.

9. Graydon, J., Galloway, S., Palmer-Wickham, S., Harrison, D., Rich-van der Bij, L., West, P., Burlein-Hall, S., \& Evans-Boyden, B., (1997): Information needs of women during early treatment for breast cancer. J Adv Nurs. Jul, Vol.26 (1) : pp 59-64.

10. Harding, V., Afshar, M ., Krell, J., Ramaswami, R., Twelves, C., \& Stebbing, J., (2013): Being there for women with metastatic breast cancer: a pan-European patient survey, British Journal of Cancer Vol. 109: pp15431548.

11. Huang, G., \& Penson, D., (2008): Internet health resources and the cancer patient. Cancer Investig,Vol. 26 (2): pp 202-207.

12. Kassianos, A., Raats, M., \& Gage, H., (2016): An Exploratory Study on the Information Needs of Prostate Cancer Patients and Their Partners, Health Psychology Research, Vol.4 (1): pp 4786.

13. Kimiafar, K., Sarbaz, M., Sales, S., Esmaeili, M., \& Ghazvini, Z., (2016): Breast cancer patients' information needs and informationseeking behavior in a developing country, National Center for Biotechnology Information ,Vol .28: pp 156-160.

14. Mohamed, L., \& El-Sebaee, H., (2013): Comparison of Informational Needs among Newly Diagnosed Breast Cancer Women Undergoing Different Surgical Treatment Modalities , Journal of Biology, Agriculture and Healthcare, Vol.3 (13): pp73-84.

15. Montazeri, A., Vahdaninia, M., Harirchi, I., Harirchi, A., Sajadian, A., Khaleghi, F., Ebrahimi, M., Haghighat, S., \& Jarvandi, S., (2008): Breast Cancer in Iran: Need for Greater Women Awareness of Warning Signs and Effective Screening Methods, Asia Pacific Family Medicine, Vol .7 (1): p.6.

16. Nagler, R., Gray, S., Anca, R., Kelly, B., Angela, A., Katrina, S., Sanford, H., \& Robert, C., (2010): Differences in information seeking among breast, prostate, and colorectal cancer patients: results from a population-based survey. Patient education and counseling. Vol. 81 (1): pp 54-62.

17. Pakseresht, S., Ingle, G., Bahadur, A., Ramteke, V., Singh, M., Garg, S., \& Agarwal, P., (2009): Risk factors with Breast Cancer among Women in Delhi. Indian Journal of Cancer, 46 (2): pp 132-138.

18. Polly, W., Winnie, K., Daniel Y., Liza Y., Joe C., \& Lau, S., (2011): The Information Needs of 
Breast Cancer Patients in Hong Kong and Their Levels of Satisfaction With the Provision of Information, Cancer Nursing ,Vol .34 (1): pp 49-57.

19. Sandhu, D., Sandhu, S., Karwasra, R., \& Marwah, S., (2010): Profile of Breast Cancer Patients at A Tertiary Care Hospital in North India. Indian Journal of Cancer, Vol .47 (1): pp.16-22.

20. SheaBudgell, M., Kostaras, X., Myhill, K., \& Hagen, N., (2014): Information needs and sources of information for patients during cancer follow-up, Curr Oncol ,Vol.21 (4): pp 165-173.

21. Smeltzer, S., Hinkle, J., Bare, B., \& Cheever, K., (2014): Text book of medical surgical ,13th (ed), vol .1: pp1472.

22. Sohag Hospital Statistical Record (2014).

23. Syeed, N., (2011): A Study Of awareness About Breast Cancer And Practice Of Breast SelfExamination Amongfemale Respondents Indhaka, East West University, Vol .1: pp1-71.

24. Tariman, J., Doorenbos, A., Schepp, K., Singhal, S. , \& Berry, D., (2014): Information Needs Priorities in Patients Diagnosed With Cancer: A Systematic Review, Vol.5 (2): pp115122.

25. Tracee, C., (2009): Breast Cancer Facts, Health's Disease and Condition .reviewed by Medical Review Board. available at http:womanhealth.about.com/bio/Tracee-

26. Valero-Aguilera, B., Bermúdez-Tamayo, C., García-Gutiérrez, J., Jiménez-Pernett J ., Cózar-Olmo, J., Guerrero-Tejada, R., and Alba-Ruiz, R., (2014): Information needs and Internet use in urological and breast cancer patients , Supportive Care in Cancer,Vol. 22 ( 2): pp 545-552

27. Yi, M., Cho, J., Noh, D., Song, M., Lee, J., \& Juon, H., (2007): Informational Needs of Korean Women with Breast Cancer: CrossCultural Adaptation of the Toronto Informational Needs Questionnaire of Breast Cancer. Journal of Asian Nursing Research,Vol.1 (3): pp 176-18.

28. Zaid, Y., Egberongbe, H., \& Adekanye, A., (2016): Needs and sources of information for women in the treatment and management of breast cancer in Lagos State, University Library,Vol. 32 (2): pp175-185. 